\title{
Human post-mortem synapse proteome integrity screening for proteomic studies of postsynaptic complexes
}

\author{
Àlex Bayés ${ }^{1,2}$, Mark O Collins ${ }^{3}$, Clare M Galtrey ${ }^{4}$, Clémence Simonnet ${ }^{5}$, Marcia Roy ${ }^{5}$, Mike DR Croning ${ }^{5}$, Gemma Gou ${ }^{1,2}$, \\ Louie N van de Lagemaat ${ }^{5}$, David Milward ${ }^{6}$, lan R Whittle ${ }^{5}$, Colin Smith ${ }^{7}$, Jyoti S Choudhary ${ }^{8}$ and Seth GN Grant ${ }^{5^{*}}$
}

\begin{abstract}
Background: Synapses are fundamental components of brain circuits and are disrupted in over 100 neurological and psychiatric diseases. The synapse proteome is physically organized into multiprotein complexes and polygenic mutations converge on postsynaptic complexes in schizophrenia, autism and intellectual disability. Directly characterising human synapses and their multiprotein complexes from post-mortem tissue is essential to understanding disease mechanisms. However, multiprotein complexes have not been directly isolated from human synapses and the feasibility of their isolation from post-mortem tissue is unknown.

Results: Here we establish a screening assay and criteria to identify post-mortem brain samples containing well-preserved synapse proteomes, revealing that neocortex samples are best preserved. We also develop a rapid method for the isolation of synapse proteomes from human brain, allowing large numbers of post-mortem samples to be processed in a short time frame. We perform the first purification and proteomic mass spectrometry analysis of MAGUK Associated Signalling Complexes (MASC) from neurosurgical and post-mortem tissue and find genetic evidence for their involvement in over seventy human brain diseases.

Conclusions: We have demonstrated that synaptic proteome integrity can be rapidly assessed from human post-mortem brain samples prior to its analysis with sophisticated proteomic methods. We have also shown that proteomics of synapse multiprotein complexes from well preserved post-mortem tissue is possible, obtaining structures highly similar to those isolated from biopsy tissue. Finally we have shown that MASC from human synapses are involved with over seventy brain disorders. These findings should have wide application in understanding the synaptic basis of psychiatric and other mental disorders.
\end{abstract}

Keywords: Synapse, Proteomics, Mass spectrometry, Supercomplex, Post-mortem brain, MAGUK, Psychiatric disorder

\section{Background}

Synapse proteomics involves the comprehensive analysis of individual synapse proteins and their organization and assembly into multiprotein complexes [1]. Proteomic mass spectrometry analysis of mammalian synapses demonstrated that synapse proteomes are highly complex with over 1000 proteins in humans [2,3]. This knowledge, combined with human genetic studies, enabled the systematic identification and classification of human

\footnotetext{
* Correspondence: seth.grant@ed.ac.uk

${ }^{5}$ Genes to Cognition Programme, Molecular Neuroscience, Centre for Clinical Brain Science and Centre for Neuroregeneration, University of Edinburgh, Edinburgh EH16 4SB, UK

Full list of author information is available at the end of the article
}

diseases involving synapse proteins, which are now referred to as Synaptopathies [4]. Several reports [5-9] show it is feasible to profile individual proteins in the human postsynaptic density (PSD) proteome from postmortem tissue and three studies in Alzheimer's Disease $[7,8]$ and alcohol addiction [9] show the potential for direct molecular studies of synaptopathy.

To date there are no proteomic studies of synaptic multiprotein complexes from either post-mortem (PM) or neurosurgical biopsy (NSB) material. In mice virtually all synapse proteins are assembled into supramolecular complexes, some of which are in turn assembled into supercomplexes $[10,11]$. These can be isolated using a 
variety of affinity purification methods including peptides, chemical ligands, antibodies and genetically encoded affinity tags $[4,12,13]$. The prototype postsynaptic supercomplexes are known as MASC (MAGUK Associated Signalling Complexes) and they are organized around scaffolding proteins encoded by the DLG/MAGUK gene family. Humans and mice have 4 DLG paralogues: DLG1/ SAP97, DLG2/PSD93, DLG3/SAP102 and DLG4/PSD95. MASCs were originally characterized from mouse brain and are $\sim 2 \mathrm{MDa}$ in size, containing, among other proteins, glutamate receptors, signalling proteins and potassium channels [12,14]. The importance of MASCs for cognition is emphasized by human genetic studies of mental disorders including schizophrenia, autism, intellectual disability and other diseases, which show mutations in MASC components [15-18]; similarly, mutations of MASC genes in mice also result in cognitive impairments [4,19-21].

To better understand synaptic biochemical variations in health and disease, the ability to isolate and characterize MASC from PM human brain is critical. Unfortunately, the greatest obstacle to human synapse proteomics is the protein degradation that occurs due to ante- and postmortem conditions. Although brain banks report indices for assessing sample quality such as PM time interval, tissue $\mathrm{pH}$ and an RNA integrity index (RIN), their relevance for proteome integrity is unknown. Here we have surveyed the variability and suitability of PM tissue with the purpose of isolating and characterizing postsynaptic protein complexes using proteomics. We report that standard brain quality indicators from tissue banks poorly predict the integrity of the postsynaptic proteome and we have developed a new index that is a robust correlate of synapse proteome integrity allowing proteomic analysis of MASC from PM samples. These studies and their data resources reveal the importance of human MASC in a large number of human diseases. The new approaches will also facilitate isolation of other synapse multiprotein complexes and their direct study in diseased tissue. All the data generated in this study is freely available in the G2Cdb database (http://www.genes2cognition.org/ publications/human-masc).

\section{Results and discussion}

Rapid isolation of postsynaptic fractions from small PM samples

Our initial objectives were to: i) enhance sample preparation speed to improve preservation of protein complexes and allow greater numbers of samples to be analysed, and ii) increase protein yield enabling studies on small amounts of tissue. We reduced the duration of the isolation of postsynapse-enriched fractions from 6-8 $\mathrm{h}$ [22] to 2 hours by removing the density gradient fractionation step and maintaining the well-known nonionic detergent insolubility of the PSD of excitatory synapses (Figure 1A, see methods). The high protein yield $(2.8 \pm 0.13 \mu \mathrm{g}$ SEM, $\mathrm{n}=35$ protein in $\mathrm{P} 2$ fraction $/ \mathrm{mg}$ of tissue) of this protocol enabled a 10 -fold reduction in the amount of starting material permitting routine isolation of synaptic-enriched structures from as little as $100 \mathrm{mg}$ of human brain tissue. Enrichment of synapse proteins in the P2 fraction was confirmed (Figure 1B,C).

Next, we applied this protocol to 28 randomly selected PM brains from the MRC Edinburgh Brain Bank (Additional file 1) and assessed the degradation of 20 important postsynaptic proteins using immunoblotting (Additional file 2: Figure S1). Comparison with control NSB tissue (Additional file 2: Figure S1) permitted counting and scoring of the integrity of each protein in each PM sample. The correlation coefficient for the number of intact proteins in each sample compared with Brain Bank quality indicators including RNA integrity, time since death and other measures (Table 1) was calculated. We failed to find statistical significance in any of these correlations, indicating these measures do not reliably predict synapse proteome integrity; which triggered us to develop a new method to evaluate synaptic proteome integrity that could be readily applied to PM samples.

\section{A simple screening method to measure PM synapse proteome integrity}

Inspection of these 20 immunoblots (Additional file 2: Figure S1) revealed that PM samples in GluN2B (2B subunit of the N-methyl-D-aspartate glutamate receptor) presented two low-molecular weight bands (see bands 2 and 3 on Figure 1D) that corresponded with GluN2B proteolysis products due to PM conditions as described previously [23]. These degradation products, which are absent from biopsy samples (NSB, Figure 1D), are already apparent $2 \mathrm{~h}$ after death [23]. Different PM samples showed different intensities for these three bands; for instance, some samples lacked all three bands (sample 18/07) indicating complete degradation of the receptor and some lacked only the uppermost Band 1 (samples 19/06 or 19/08) indicating partial degradation. To estimate the extent of degradation of each sample, the ratio of Band 1/Band 2 intensity was measured for all 28 samples (median ratio: 0.83). We next correlated these values with the counts of present immunoblotted PSD proteins (Additional file 2: Figure S1) and in contrast to what was observed with brain bank indicators, we found significant positive correlation (Spearman's rho $=0.59, \mathrm{P}<0.001$, Figure $1 \mathrm{E})$. These results suggest this ratio can be used to estimate synaptic proteome preservation in PM brain samples and hereafter we refer to this ratio as HUSPIR (HUman Synapse Proteome Integrity Ratio).

To validate the usefulness of HUSPIR we prospectively screened another group of nine PM samples (Selected 


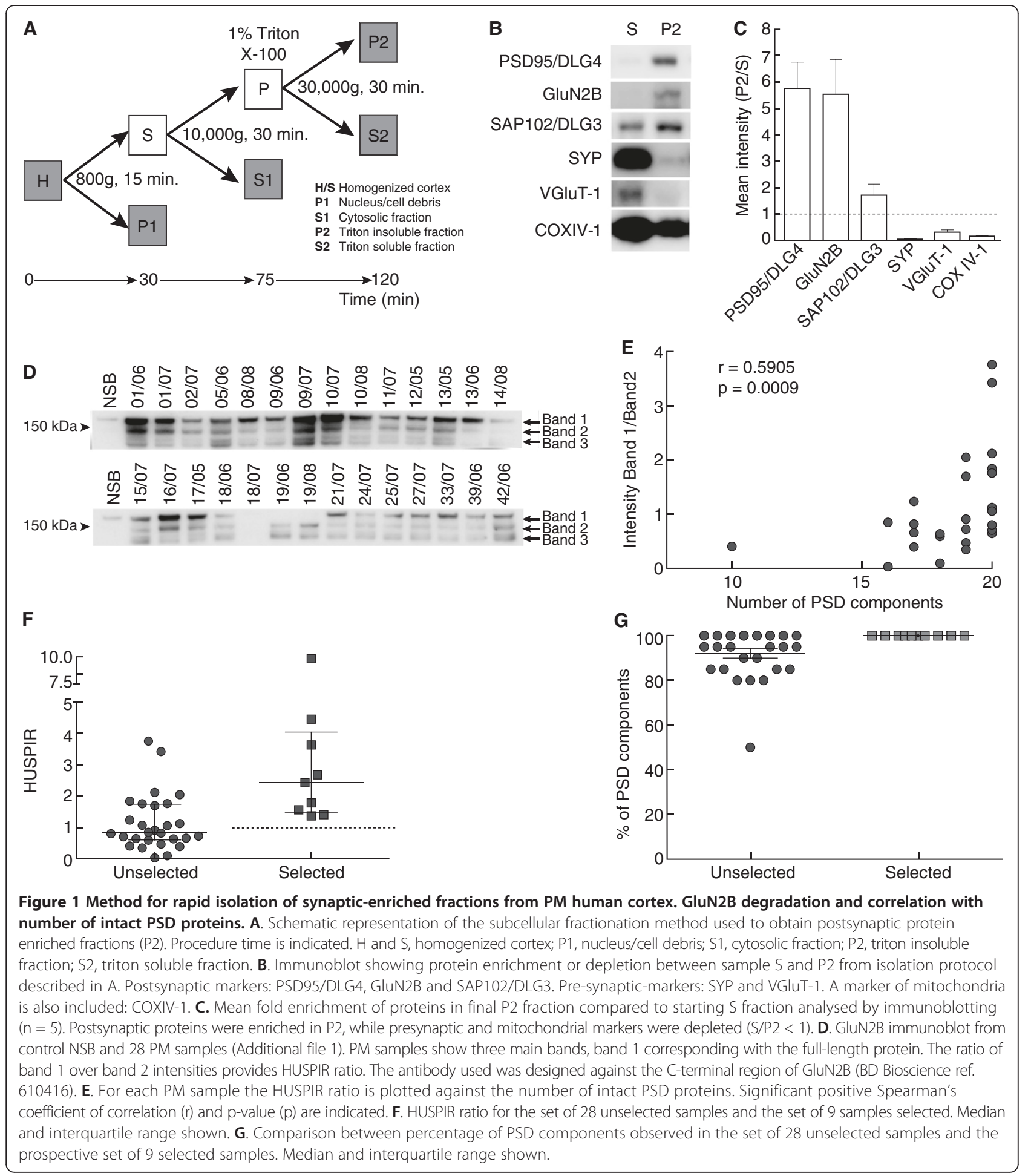

PM Group) that were presumed to be of high quality since they were obtained from individuals who died suddenly, before the age of 60 , had a short agonal state and PM interval, and showed no detectable neuropathological abnormalities. The median HUSPIR value for this group (2.43, Figure $1 \mathrm{~F})$ was significantly higher $(\mathrm{p}=0.001$; Mann
Whitney Test) than the median HUSPIR for the initial set (Unselected PM Group, Figure 1F). As predicted by HUSPIR the selected group presented all PSD components analysed by immunoblotting (Figure $1 \mathrm{G}$ and Additional file 2: Figure S2). These results confirm that the simple and rapid measurement of HUSPIR, based on GluN2B 
Table 1 Correlation between brain bank tissue quality parameters and number of detected postsynaptic density proteins

\begin{tabular}{lll}
\hline Parameter & Spearman $\mathbf{r}$ & p value (two-tailed) \\
\hline PM Interval $(n=28)$ & 0.01079 & 0.9566 (n.s.) \\
pH $(n=25)$ & -0.075 & 0.1193 (n.s.) \\
RNA Integrity Number & 0.1193 & 0.6163 (n.s.) \\
$\begin{array}{l}\text { RIN) }(n=20) \\
\text { Intensity of GluN2B Band }\end{array}$ & 0.5905 & $0.0009(* * *)$ \\
$\begin{array}{l}\text { 1/Band 2 ( } n=28) \\
\text { Intensity of GluN2B Band }\end{array}$ & -0.01091 & 0.956 (n.s.) \\
$\begin{array}{l}\text { 1/Band 3 ( } n=28) \\
\text { Intensity of GluN2B Band }\end{array}$ & 0.4831 & $0.0092(* *)$ \\
1/Band 2 + Band 3 ( $n=28)$ & & \\
\hline
\end{tabular}

Number in brackets indicates the number of tissue samples (out of 28 ) with a value for that particular parameter; n.s. not significant; ${ }^{* *} p<0.001$ and ${ }^{* *} p<0.01$.

band ratios, reliably predicts synapse proteome integrity. Based on these results, we propose using PM samples with a HUSPIR $>1$ for biochemical evaluation.

\section{Synaptic proteome integrity varies between cortical and other brain regions}

We were also interested in evaluating if postsynaptic proteome integrity was homogenous between different areas of the same brain. To address this issue we isolated postsynaptic densities (PSD) from 26 different brain regions in 4 different post-mortem brains from the 'sudden-death brain bank collection' (Edinburgh MRC-Brain Bank). These regions included 13 cortical areas, 5 limbic structures and 8 sub-cortical regions (Figure 2). Each isolated PSD fraction was subjected to GluN2B immunoblot (Figure 2A,B) to determine its corresponding HUSPIR value.

As summarized in Figure $2 \mathrm{C}$ HUSPIR values varied between cortical and other brain regions. While most HUSPIR values for cortical regions were above 1, suggesting a good preservation of its postsynaptic proteome, other brain regions showed a HUSPIR $<1$ in more than half of the samples analysed (34/52; Figure 2C). The fact that limbic areas anatomically close to the cortex (cingulate gyrus: BA23 and BA24) show high HUSPIR values in the 4 brains analysed gives further evidence for a better preservation of the synaptic proteome in more anterior brain regions. Finally, this data also indicates that when working with non-cortical brain areas HUSPIR should be measured for each brain sample included in the study. The HUSPIR value of one cortical region has a good predictive value for other cortical regions of the same brain, as shown in Figure 2C.

\section{Isolation and proteomics of human MAGUK associated signalling complexes}

In the next phase of our study we have combined the new methods for screening samples with well preserved synaptic proteomes with affinity methods to isolate MAGUK Associated Signalling Complexes (MASC). This affinity method relies on a 6 amino acid immobilized peptide (pep6, SIESDV) that binds to PDZ domains of MAGUK proteins and a control peptide (pep6 $\delta$ V, SSIESD) that cannot bind to these domains [24]. We used this protocol, which involves the use of stringent biochemical methods, to ask if it was possible to isolate MASC from 3 PM human frontal cortex samples with HUSPIR $>1$ (Additional file 1). As a positive control we used the same protocol on 3 NSB samples and as a further positive control, we also isolated MASCs from mouse cortex. As shown in the coomassie stained SDS-PAGE gel (Figure 3A), all samples showed strong recovery of multiple proteins with pep6, and as expected, a low background with pep6 $6 \mathrm{~V}$ purifications. Immunoblotting of these samples with antibodies to three MAGUK proteins (DLG2/PSD93, DLG3/ SAP102, DLG4/PSD-95) showed robust signals in pep6 samples and no signal in negative controls (Figure 3B). These results show that it is possible to affinity isolate MASCs from NSB as well as PM human brain and we hereafter refer to these isolates as hMASC.

We next identified all proteins in hMASC samples using mass spectrometry and used bioinformatics to compare PM and NSB components (Additional file 3). See Additional file 2 for detailed bioinformatics functional analysis of hMASC. In total we found 239 and 227 proteins in NSB and PM hMASC respectively. A very large proportion (>75\%) of NSB hMASC proteins were found in PM hMASC complexes, demonstrating for the first time that it is possible to isolate bona fide synaptic multiprotein complexes from PM samples if these have a HUSPIR value $>1$. These results also indicate the applicability and robustness of the affinity isolation methods developed here to analyse human PM brain tissue. Comparison of the functional types of proteins in PM and NSB hMASC showed a high similarity (Figure $3 \mathrm{C}$ and Additional file 4).

Despite the high degree of similarity between NSB and PM hMASCs we reasoned that some protein types are likely more vulnerable to PM conditions than others. If this is the case it is important to identify them, as these will be underrepresented in PM hMASCs. We analysed several protein features, including protein length, isoelectric point, presence of transmembrane regions, and protein turn-over [25], in proteins isolated from both tissue sources. Overall, proteins found in NSB and PM hMASCs showed only minor differences among these variables. Only protein length was slightly biased, with proteins found in two or three triplicate samples somewhat longer in NSB hMASC compared to PM hMASC (median length 558, compared to 428 residues, respectively; $\mathrm{p}=0.033$, Mann Whitney Test). Next we compiled a list of the specific proteins with differential expression 

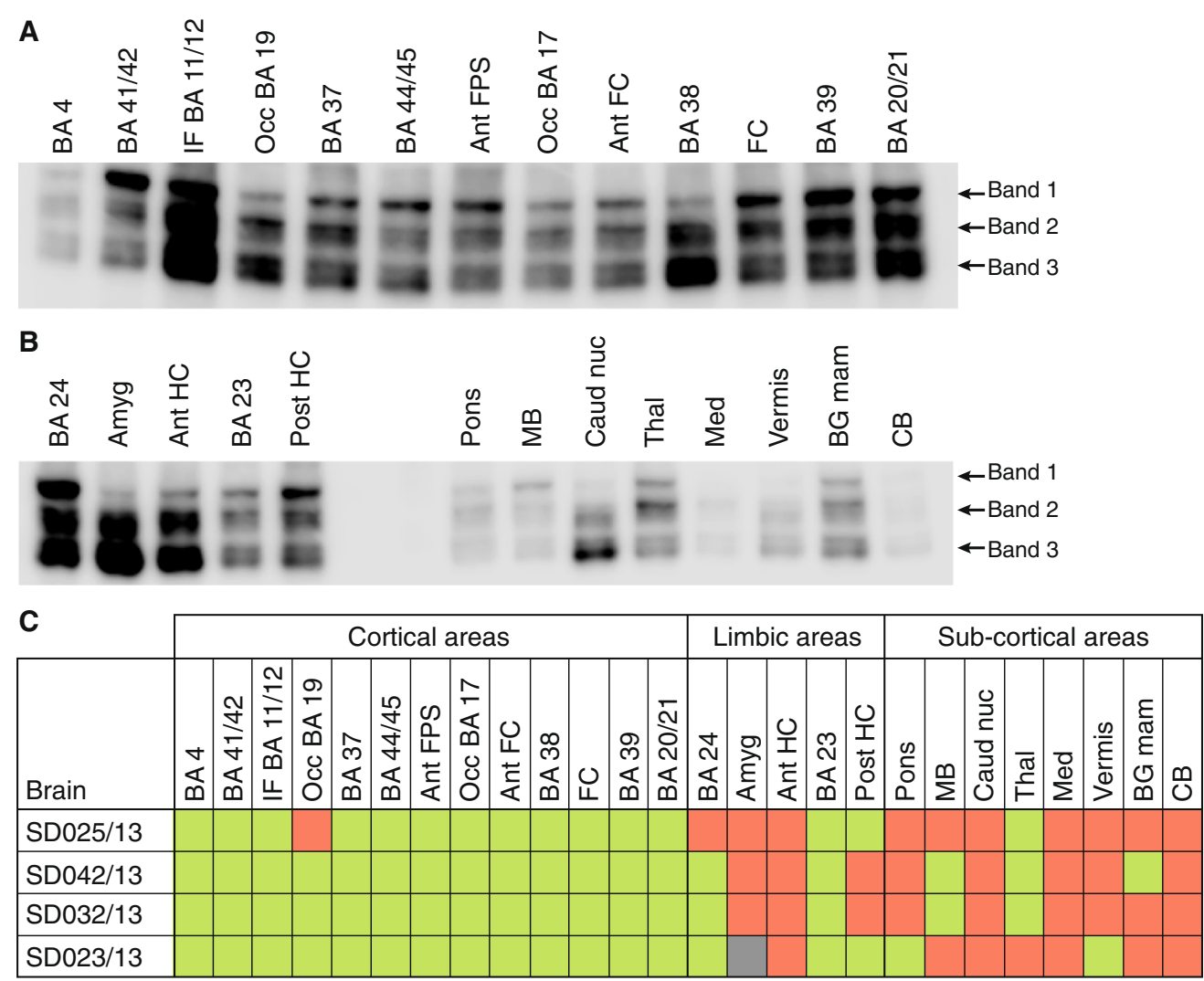

Figure 2 Comparative GluN2B degradation between brain areas. A. Representative immunoblot of GluN2B for 13 different cortical regions from brain SD025/13 (Additional file 1). These cortical regions included the Broadmann Areas (BA) 4, 11/12, 17, 19, 20/21, 37, 38, $39,41 / 42$ and 44/45 (Broca's area), as well as three frontal cortex samples: frontal convexity (FC), anterior frontal convexity (Ant FC) and anterior frontal parasagital (Ant FPS). GluN2B degradation bands are indicated. B. Representative immunoblot of GluN2B for 5 limbic areas: Broadmann areas (BA) 23 and 24, anterior and posterior Hipocampus (HC) and amygdala (Amyg); and 8 sub-cortical regions: Pons, Midbrain (MB), Caudate nucleus (Caud nuc), Thalamus (Thal), Medulla (Med), Vermis, Basal ganglia mammillary body (BG mam) and Cerebellum (CB). GluN2B degradation bands are indicated. C. Plot summarizing HUSPIR values for 26 brain areas (13 cortical, 5 limbic and 8 sub-cortical) analysed by immunoblot for GluN2B degradation in 4 different brains (SD025/13, SD042/13, SD032/13 and SD023/13). HUSPIR values above one are indicated in green and below in red. Grey indicates no measure could be taken.

and noted this included proteins involved with activitydependent reorganization of the synaptic proteome, including calcium-calmodulin dependent kinases (CAMK2A, B and G), scaffold proteins of the DLGAP family, G-proteins and elements of the tubulin cytoskeleton (Additional file 2: Figure S3). In contrast to these unstable components, the more stable groups included the MAGUK scaffold proteins, their associated NMDA receptors, signalling and cytoskeletal proteins, among others (Additional file 2: Figure S4).

\section{Human MASC proteins in disease}

To understand the relevance of hMASC to human disease we searched online genetics databases and the published human genetics literature for evidence of hMASC genes involved in brain disorders (see methods). Our approach involved: i) identification of relevant genes and relevant diseases, ii) allocation of diseases into specific categories according to the International classification of Disease System (ICD-10), iii) statistical analysis of the representation of disease categories, and iv) comparison of hMASC with hPSD to examine the relative importance of hMASC, as compared with the whole postsynaptic density.

According to OMIM database of inherited diseases [26] 66 hMASC genes are involved with 93 genetic diseases. Fifty-one of these are nervous system diseases with 47 specific to the CNS. Literature text-mining and curation identified CNS diseases for which hMASC genes were positively associated, bringing the total number of CNS diseases related to the hMASC to 76 . Classification with ICD-10 of these CNS diseases showed they include rare monogenic disorders as well as complex, more common psychiatric and neurologic disorders, including Schizophrenia and Autism spectrum disorder (Additional file 5). We next asked whether particular disease categories were over- or under-represented in hMASC compared to the postsynaptic proteome (hPSD, see Bayés et al. [2]). Looking into inherited diseases, we found a two-fold greater proportion of hMASC 


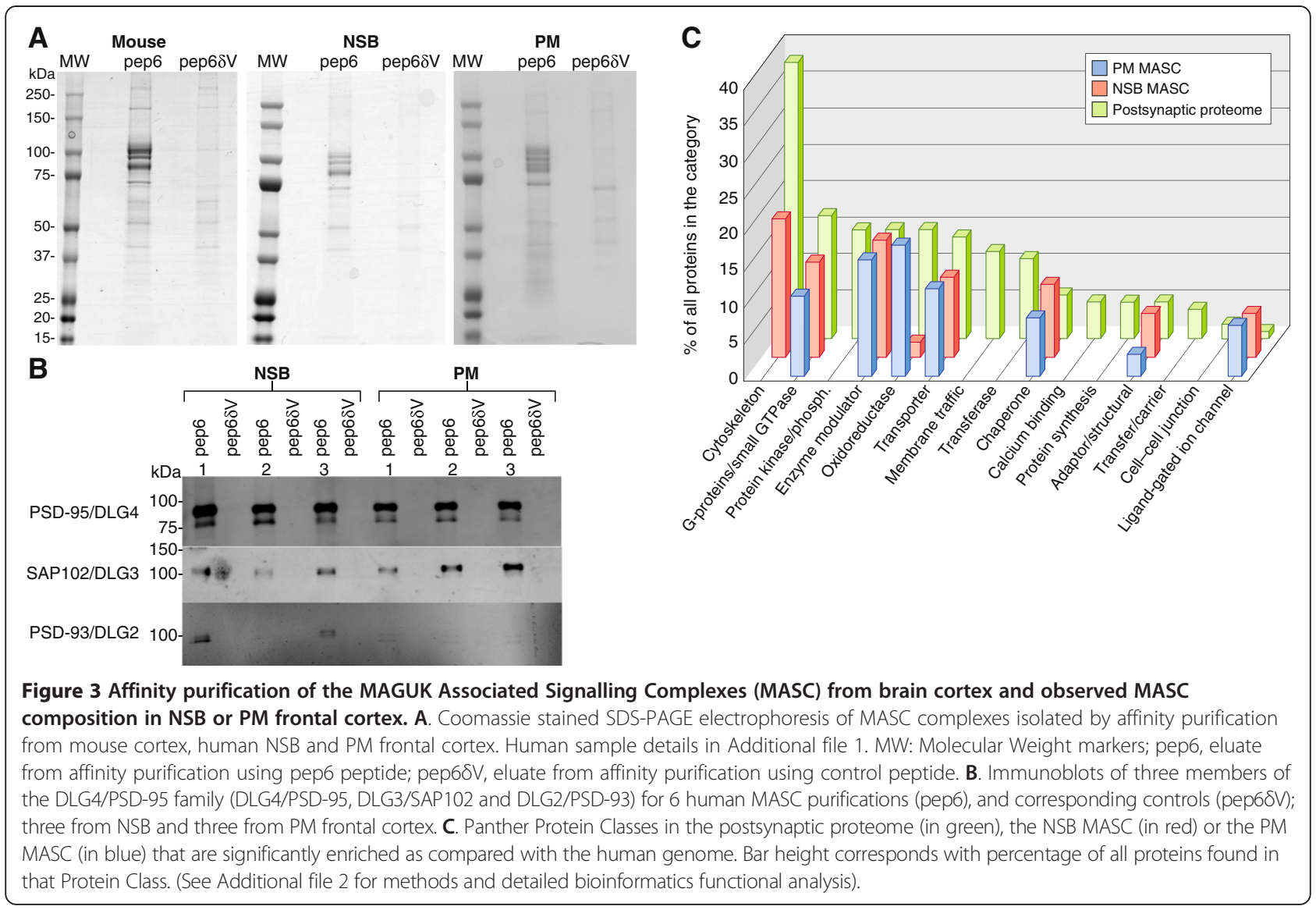

genes (both NSB and PM) involved with CNS compared with hPSD genes (Figure 4A). As shown in Figure 4B, the 'Disorders of the Nervous System' and 'Mental and Behavioural Disorders' ICD-10 categories were over-represented relative to the hPSD, whereas the hPSD was more enriched in Endocrine, Nutritional and Metabolic Diseases than hMASC (Figure 4B). As hMASC was most enriched for Mental \& behavioural Disorders, we examined Intellectual Disability disorders in more detail. We created a database of genes causing any form of ID (ID) and nonsyndromic ID (NSID) (Additional file 6) and found a significant over-representation of hMASC and hPSD genes in both these types of ID, with NSID highest (Figure 4C,D).

\section{Conclusions}

We developed a simple method for determining if the synapse proteome integrity of a PM sample is sufficient for proteomics and rapid biochemical methods for the isolation of synapse-enriched fractions from small amounts of human PM tissue. In around two hours, synaptic proteomes can be obtained from as little as $100 \mathrm{mg}$ of starting tissue, allowing for the parallel analysis of large numbers of samples. We have also shown that the HUman Synaptic Proteome Integrity Ratio (HUSPIR), an indicator of postsynaptic proteome integrity, denotes that the synaptic proteome is better conserved in cortical than other brain regions. Using these approaches we have also performed the first isolation and proteomic characterization of human MAGUK Associated Signalling Complexes and identified $76 \mathrm{CNS}$ diseases involving MASC proteins, of which 47 are inherited disorders. The centrality of hMASC to human synapse function and human synaptic diseases is evidenced by the comparison of the hMASC and hPSD proteomes and their relevant genetic diseases.

Of the many diseases impacting on the synapse, hMASC is particularly important for those with cognitive components including ID, schizophrenia and autism. Recent whole exome analyses of schizophrenia show convergence of multiple mutations onto hMASC $[15,16]$ and population studies show IQ is associated with genetic variation in hMASC genes [27]. Comparison of human and mouse synapse proteome orthologues shows a high degree of conservation in MASC and PSD proteins consistent with conserved functions [2]. Moreover, comparative cognitive testing with computerized touchscreen tests show MAGUK proteins in both species have conserved regulation of cognitive components [21].

Future studies on human synapse proteomes could use the Human Synapse Proteome Integrity Ratio (HUSPIR) to identify PM samples suitable for sophisticated 

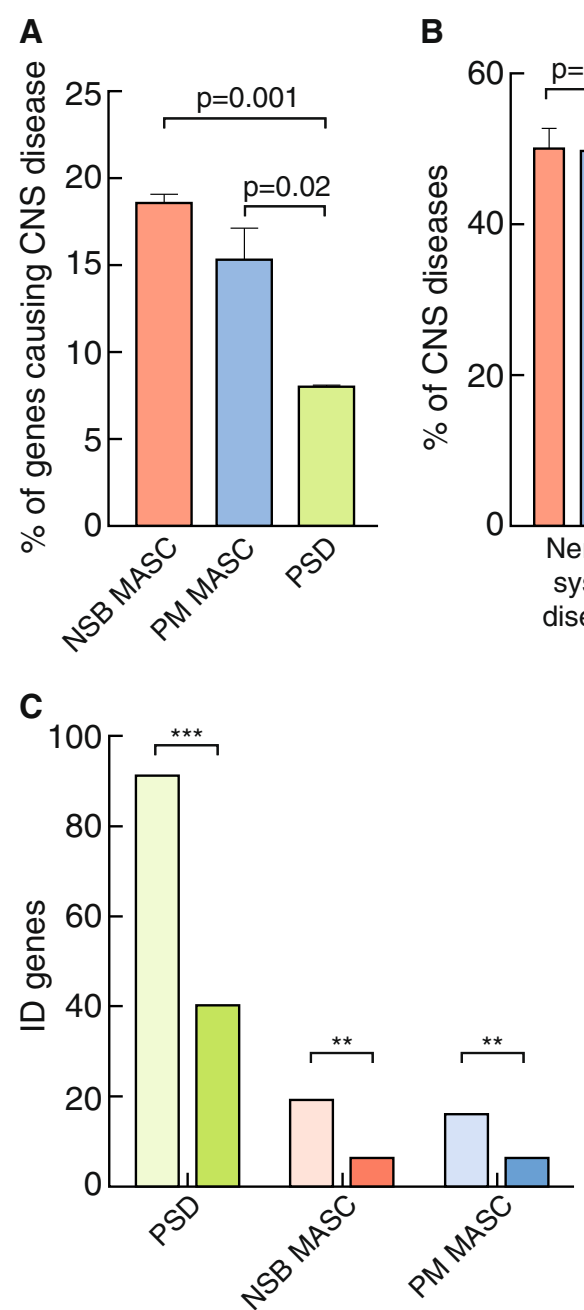
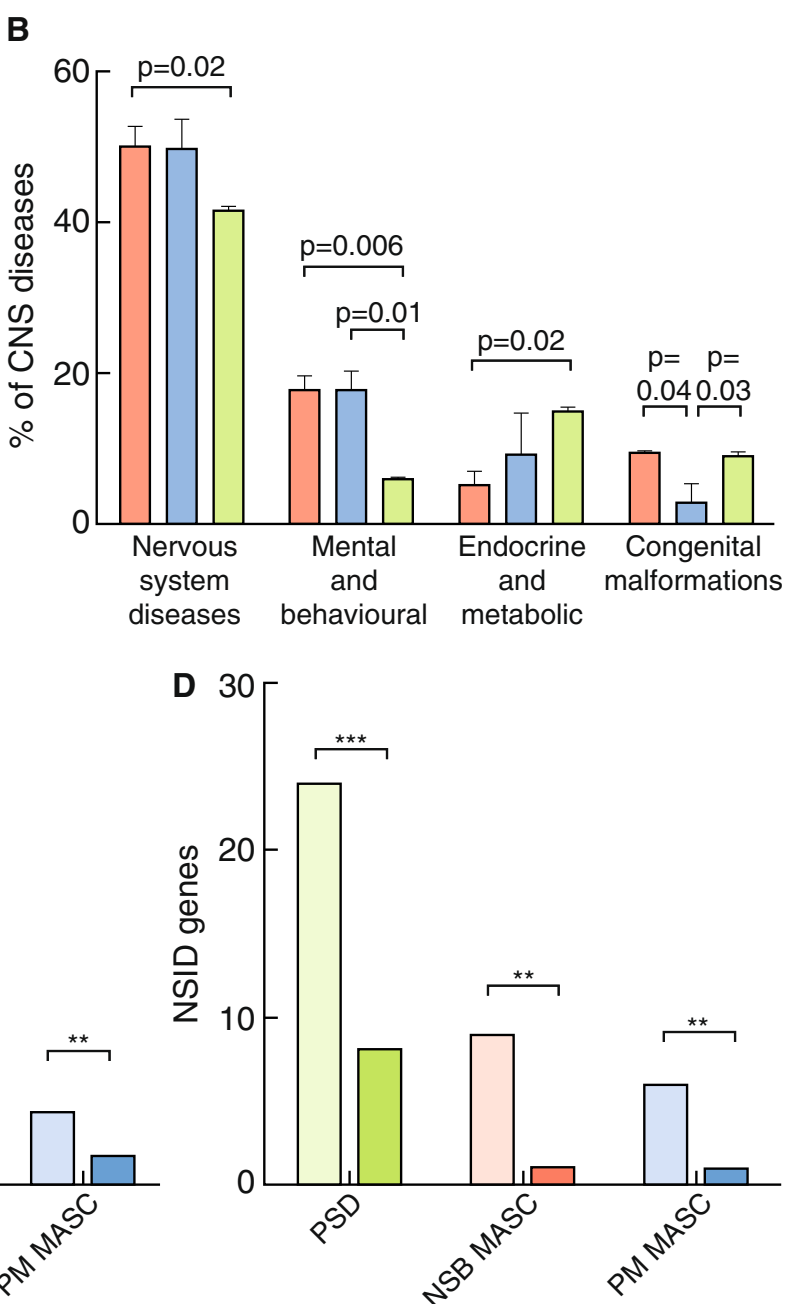

Figure 4 Involvement of MASC proteins in genetic diseases. A. Percentage of genes expressed in human NSB MASC, PM MASC and PSD causing central nervous system diseases included in OMIM. B. Proportion of CNS diseases caused by genes found in human NSB MASC (red), PM MASC (blue) and PSD (green). ICD-10 groups (Chapters) indicated on x-axis: Congenital Malformations refers to ICD-10 Chapter XVII, Nervous System Diseases refers to ICD-10 Chapter VI, Endocrine and metabolic refers to ICD-10 Chapter IV and Mental and Behavioural refer to ICD-10 Chapter V. Means compared by Student's t-test. C. Genes expressed at the postsynapse causing any form of genetic Intellectual Disability (ID). For each postsynaptic protein complex pale columns indicate number of genes causing ID and dark columns the expected number to be found by chance. Binomial statistics are used to compute significance of the difference between observed and expected (Binomial Statistics, ***, $\mathrm{p}<1 \mathrm{E}-05$; **, $\left.p<1 \mathrm{E}-03 ;{ }^{*}, p<0,05\right)$. D. Genes expressed at the postsynapse causing any form of genetic non-syndromic Intellectual Disability (NSID). For each postsynaptic protein complex pale columns indicate number of genes causing ID and dark columns the expected number to be found by chance. Binomial statistics are used to compute significance of the difference between observed and expected (Binomial Statistics, ***, $\mathrm{p}<1 \mathrm{E}-05$; **, $\left.\mathrm{p}<1 \mathrm{E}-03 ;{ }^{*}, \mathrm{p}<0,05\right)$.

proteomics from the thousands of stored brain bank samples. We were surprised to find that $\sim 30 \%$ of cortical samples in the Edinburgh Brain Bank met the criteria of a HUSPIR $>1$, which suggests that large numbers of samples are suitable for analysis. Quantitative analysis of whole synapses or their subcomponents including hMASC can now be applied on a large scale to characterize human synaptopathies directly in human tissue. In addition to the use of HUSPIR, the identification of stable proteins indicates that these proteins and their relevant diseases will be better suited for study than those involving labile proteins. Synapse proteomics has identified a striking number of diseases that impact on the synapse and further development of methods for the study of human synaptopathy may have a major impact on neuropathology and diagnosis in the future. All the data generated in this study is freely available in the G2Cdb database (http://www. genes2cognition.org/publications/human-masc). 


\section{Methods}

\section{Human neocortex samples}

NSB samples were obtained from frontal cortex by Prof. Ian Whittle (Edinburgh University) in a study approved by the Lothian Region Ethics Committee (/2004/4/16). Informed consent was obtained from all donors. All PM tissue was obtained from the Medical Research Council Edinburgh Brain Bank (Additional file 1). The three PM samples used to purify MASC were from the frontal cortex (Additional file 1).

\section{Rapid isolation of postsynaptic fractions from PM tissue}

To facilitate characterization of the human postsynaptic proteome we developed biochemical methods based on those used in rodents [28,29]. Approximately $300 \mathrm{mg}$ of grey matter was routinely used for isolation of synaptic fractions; nevertheless, the protocol can be scaled down to $100 \mathrm{mg}$ of starting material. Prior to tissue processing, white matter was removed from frozen cortex blocks. Grey matter was homogenized with a glass-teflon dounce (tissue weight: volume ratio of $100 \mathrm{mg}: 1 \mathrm{ml}$ ) in a buffer containing 0.32 M sucrose, $10 \mathrm{mM}$ HEPES pH 7.4, $2 \mathrm{mM}$ EDTA, $5 \mathrm{mM}$ sodium o-vanadate, $30 \mathrm{mM} \mathrm{NaF}$ and protease inhibitors cocktail (Roche). Homogenized tissue was centrifuged at $800 \times \mathrm{g}$ for $15 \mathrm{~min}$ at $4^{\circ} \mathrm{C}$; supernatant removed and centrifuged at $10,000 \times \mathrm{g}$ for $15 \mathrm{~min}$. The pellet was resuspended in Triton buffer (50 mM HEPES pH 7.4, 2 mM EDTA, 5 mM EGTA, 5 mM sodium-Ovanadate, $30 \mathrm{mM} \mathrm{NaF}, 1 \%$ Triton $\mathrm{X}-100$ and protease inhibitors cocktail (Roche)) with half the volume used for homogenization. Sample was then centrifuged at 30,000 $\times$ g for $30 \mathrm{~min}$ at $4^{\circ} \mathrm{C}$ and the final pellet was resuspended in $200 \mu \mathrm{l}$ of SDS buffer (50 mM Tris $\mathrm{pH} 7.4,1 \%$ SDS) and used for immunoblotting.

\section{Isolation of postsynaptic densities from human post- mortem brain samples}

Postsynaptic densities were isolated using standard differential ultracentrifugation methods. Briefly, dissected tissues was homogenized in buffer A (0.32 M sucrose, 2 mM HEPES, pH 7.4, EDTA-free protease inhibitor cocktail (Roche), phosphatase inhibitor cocktail set II (Calbiochem) using a Dounce homogenizer. The resulting homogenate was centrifuged at $1000 \times \mathrm{g}$ for $10 \mathrm{~min}$ at $4^{\circ}$ C. The pellet was rehomogenized in the same buffer and centrifuged at $1000 \times \mathrm{g}$ for $10 \mathrm{~min}$ at $4^{\circ} \mathrm{C}$. The two supernatants were pooled and centrifuged at $18600 \times \mathrm{g}$ for 15 $\min$ at $4^{\circ} \mathrm{C}$. The next pellet was resuspended in buffer $\mathrm{B}$ (1.5 $\mathrm{M}$ sucrose and $50 \mathrm{mM}$ Tris $-\mathrm{HCl}, \mathrm{pH} 7.4$ containing the same protease and phosphatase inhibitors as in buffer A). A discontinuous sucrose gradient was built by layering equal volumes of the resuspended pellet (bottom), $0.85 \mathrm{M}$ and $0.3 \mathrm{M}$ sucrose in $50 \mathrm{mM}$ Tris- $\mathrm{HCl}$, $\mathrm{pH}$ 7.4. This gradient was centrifuged at $60000 \times \mathrm{g}$ for
42 min using a MLA-55 rotor (Beckman-Coulter). The interface between $1.5 \mathrm{M}$ and $0.85 \mathrm{M}$ sucrose, corresponding to the synaptosomal fraction, was collected, diluted in 2 volumes of $50 \mathrm{mM}$ Tris $-\mathrm{HCl}, \mathrm{pH} 7.4$ and centrifuged at $48000 \times \mathrm{g}$ for $30 \mathrm{~min}$ at $4^{\circ} \mathrm{C}$. The resulting pellet was resuspended in $1.5 \%$ Triton X-100, $25 \mathrm{mM}$ Tris- $\mathrm{HCl}, \mathrm{pH} 7.4$, incubated on ice for $30 \mathrm{~min}$, layered on top of a $0.85 \mathrm{M}$ sucrose solution in $50 \mathrm{mM}$ Tris- $\mathrm{HCl}, \mathrm{pH} 7.4$ and centrifuged at $104000 \times \mathrm{g}$ for 30 min at $4^{\circ} \mathrm{C}$. The resulting postsynaptic density pellet was resuspended in $50 \mathrm{mM}$ Tris- $\mathrm{HCl}, \mathrm{pH} 7.4$ and $10 \%$ glycerol and mixed with SDS-PAGE electrophoresis loading buffer.

\section{Isolation of human MAGUK Associated Signalling Complexes (MASC)}

MASCs were isolated from human NSB or PM frontal cortex using an improved version of an affinity purification protocol developed with mouse brain samples [12]. Briefly, this method used a peptide corresponding to the six carboxyl terminal residues of GluN2A and GluN2B, which bind PDZ domains of Membrane Associated Guanylate Kinase (MAGUK) proteins (DLG4/PSD95, DLG2/ PSD93, DLG3/SAP102 \& DLG1/SAP97) [30,31]. A negative control for the affinity purification uses a peptide lacking the C-terminal valine residue [24]. Brain tissue was homogenized (tissue weight:volume ratio of $100 \mathrm{mg}: 1.85 \mathrm{ml}$ ) with DOC Buffer (Tris $50 \mathrm{mM} \mathrm{pH} \mathrm{9.0,} \mathrm{1 \%}$ sodium deoxycholate, $50 \mathrm{mM} \mathrm{NaF}, 20 \mu \mathrm{M} \mathrm{ZnCl} 2,1 \mathrm{mM}$ Sodium o-vanadate and protease inhibitors cocktail (Roche). The homogenized sample was centrifuged at $50,000 \mathrm{~g}$ for $30 \mathrm{~min}$ and pellet discarded. For affinity purification, peptides were first bound to Affi-Gel 10 resin (Bio$\mathrm{Rad}$ ) at a $5 \mathrm{mg} / \mathrm{ml}$ concentration following manufacturers indications. Brain homogenate and peptide-bound resin were mixed at 1:100 (v/v) ratio and incubated over-night at $4^{\circ} \mathrm{C}$ with agitation. Prior to elution, resin was washed five times with 5 column volumes of DOC Buffer. Elution was performed with DOC Buffer containing free peptide at $5 \mathrm{mg} / \mathrm{ml}$. Eluted sample was reduced by adding fresh DTT (SIGMA) to a final concentration of $1 \mathrm{mM}$ and heating at $70^{\circ} \mathrm{C}$ for $10 \mathrm{~min}$. Reduced sample was carboxymethylated by adding fresh iodoacetamide (SIGMA) to final concentration of $2 \mathrm{mM}$ and incubated in the dark at room temperature for $30 \mathrm{~min}$.

\section{Sample preparation for quantitative MS}

In gel digestion was performed as reported previously [2]. Extracted peptides were isotope labelled using a triplex dimethylation strategy [32,33] and labelled peptides pooled for LC-MS/MS analysis. This was done as follows: Light labelling: Neg. Control (50\% from biopsy and 50\% from PM Pep6 $\delta$ V), Medium labelling: Biopsy Pep6, Heavy labelling: PM Pep6. Pooled peptide samples 
from each of the 12 gel bands were analysed separately by nanoLC-MS/MS on a LTQ Orbitrap Velos (Thermo Fisher) hybrid mass spectrometer equipped with a nanospray source, coupled with an Ultimate $3000 \mathrm{Nano} /$ Capillary LC System (Dionex). The system was controlled by Xcalibur 2.1 (Thermo Fisher) and DCMSLink 2.08 (Dionex). Peptides were desalted on-line using a micro-Precolumn cartridge (C18 Pepmap 100, LC Packings) and then separated using a 60 min RP gradient (4$32 \%$ acetonitrile $/ 0.1 \%$ formic acid) on a BEH C18 analytical column $(1.7 \mu \mathrm{m}, 75 \mu \mathrm{m}$ id $\times 10 \mathrm{~cm}$ ) (Waters). The LTQ-Orbitrap Velos was operated with a cycle of one MS (in the Orbitrap) acquired at a resolution of 60,000 at $\mathrm{m} / \mathrm{z} 400$, with the top 10 most abundant multiplycharged (2+ and higher) ions in a given chromatographic window subjected to MS/MS fragmentation in the linear ion trap. An FTMS target values of $1 \mathrm{e}^{6}$ and an ion trap MSn target value of $1 \mathrm{e}^{4}$ was used and with the lock mass (445.120025) enabled. Maximum FTMS scan accumulation time of $250 \mathrm{~ms}$ and maximum ion trap MSn scan accumulation time of $100 \mathrm{~ms}$ were used. Dynamic exclusion was enabled with a repeat duration of $45 \mathrm{~s}$ with an exclusion list of 500 and exclusion duration of $30 \mathrm{~s}$.

MS data was analysed using MaxQuant [34] version 1.1.1.36. Data was searched against a Human IPI sequence database (v3.68) using following search parameters: trypsin with a maximum of 2 missed cleavages, $7 \mathrm{ppm}$ for MS mass tolerance, 0.5 Da for MS/MS mass tolerance, with Acetyl (Protein N-term) and Oxidation (M) set as variable modifications and carbamidomethyl (C) as a fixed modification. A protein FDR of 0.01 and a peptide FDR of 0.01 were used for identification level cut offs. Protein quantification based on calculation of medium/light, heavy/light and heavy/medium dimethylated peptide ratios was performed using razor and unique peptides. The ratio of peptide abundances between Pep6 and Pep $\delta V$ affinity purifications was calculated independently for each protein and replicate. For a protein to be considered as a true positive in a given replicate its enrichment ratio had to be above threshold which was the sum of the median ratio and its absolute deviation (Median + MAD) [35]. Proteins with an abundance ratio above the threshold in 2 or 3 replicates were considered true components regardless of the number of peptides they have been identified with. For proteins found only in one replicate with a ratio above the threshold, to be considered a true positive, it had to be identified with at least three peptides.

\section{Analysis of MASC genes causing genetic nervous system diseases}

Gene and phenotype entries were automatically extracted from OMIM [26] using the mim2gene file linking via their Entrez Gene identifiers. Diseases caused by MASC proteins were further classified, using information in the
OMIM entry (Additional file 5), into central nervous system (CNS), peripheral nervous system (PNS), both CNS and PNS, or other. All diseases affecting the CNS, regardless of presence or absence of PNS involvement, were then grouped into chapters of the International Classification of Disease (ICD-10) developed by the World Health Organization (WHO). Those OMIM diseases that could not readily be found in ICD-10 were assigned to one of the ICD-10 chapters based on their symptoms, if possible, or classified as No-ICD 10 correspondence. Diseases in chapter VI (Diseases of the Nervous System) were divided into more specific blocks within that chapter.

To analyse the relevance of postsynaptic genes in syndromic or non-syndromic intellectual disability (ID or NSID) a list of genes known to cause these disorders was generated (Additional file 6). To create this database all genes linked to the terms "Mental Retardation" or "Intellectual Disability" were extracted from GeneCards [36] and added to a list of genes causing NSID curated from the scientific literature. Binomial statistics were used to calculate enrichment of postsynaptic components in ID or NSID.

\section{Text-mining and expert curation of MASC gene mutation associations to human nervous system disorders}

PubMed abstracts up to August 2014 were searched for Human MASC gene mutations associated to disease, using a natural language processing approach to information extraction provided in the Linguamatics I2E platform [37]. Disease and disorder ontology terms from the Medical Dictionary for Regulatory Activities dictionary (MedDRA, www.meddra.org) were combined with a flexible pattern capturing genetic mutation terms, such as mutation, polymorphism, deletion, variation, and amino acid substitution patterns such as 'K483E', requiring mutation terms to be local to the gene, but allowing the disease term to appear anywhere in the sentence. The resulting sentences were examined by a biologist, checking each for correct gene identity (disambiguation), relevance to human genetics and limiting to disorders of nervous system origin, using a simple accept/reject criterion. In the cases where many sentence 'hits' were obtained to a particular gene and disease term combination, a maximum of 10 documents were examined. Redundant disease terms, such as symptomatic terms that describe a part of a larger clinical syndrome or disease were manually removed, thus we report a single representative PubMed identifier for each gene mutation-disease association combination. We then combined the curated text-mined PubMed search results with the OMIM extraction results, to produce an overview of the relationship between reported Human MASC gene mutations and nervous system disorders. 


\section{Additional files}

\section{Additional file 1: Human Samples. Description of human samples} used in this study.

Additional file 2: Additional information, figures and figure legends on immunoblot analysis of post-mortem brain and bioinformatics functional analysis of MASC complex.

Additional file 3: Proteomic Data. List of proteins identified in the human MASC from neurosurgical and post-mortem tissue.

Additional file 4: Bioinformatics Functional Analysis. Bioinformatics functional analysis of proteins identified in human MASC from neurosurgical and post-mortem tissue.

Additional file 5: MASC genes in Disease. List of human MASC genes known to cause inherited diseases or positively associated with genetically complex psychiatric and neurologic disorders.

Additional file 6: MASC genes causing Intellectual Disability. List of human MASC genes known to cause Intellectual Disability.

\section{Abbreviations}

BA: Broadmann area; CNS: Central nervous system; hMASC: Human MASC; hPSD: Human PSD; HUSPIR: Human synapse proteome integrity ratio; ICD-10: International Classification of Disease, version 10; ID: Intellectual disability; MAGUK: Matrix associated guanilate Kinase; MASC: MAGUK associated signalling complex; NMDAR: N-methyl-D-aspartate receptor; NSB: Neurosurgical biopsy; NSID: Non-syndromic intellectual disability; PM: Post-mortem; PSD: Postsynaptic density; RIN: RNA integrity number; SEM: Standard error of the mean.

\section{Competing interests}

The authors declare that they have no competing interests.

\section{Authors' contributions}

AB, CG, CS, GG and MR performed biochemical analysis. MOC and JSC performed mass spectrometry analysis. AB, LNvdL and MDRC analysed proteomics data. MDRC LNvdL and DM performed bioinformatics, statistics and text-mining. IRW and CS provided tissue. MDRC made on-line database for this article. AB, MOC, JSC IRW, CS and SG planned and designed the research. All authors contributed to writing the manuscript. All authors read and approved the final manuscript.

\section{Acknowledgements}

Human NSB biopsies: This study was approved by Lothian Region Ethics Committee/2004/4/16, and informed consent was obtained from all donors. We thank the tissue donors, without whom this study would have been impossible.

Human PM samples: PM samples were obtained from MRC Edinburgh Brain Bank (Edinburgh). We thank the tissue donors, without whom this study would have been impossible.

AB was funded by Proyectos de investigación no orientada, BFU2012-34398, Career Integration grant CIG, Ref. 304111, Subprograma Ramón y Cajal, RYC-2011-08391. AB is thankful to Dr. Ignasi Gich -IR-HSCSP for support on biostatistical analysis.

CGM was funded by NIHR Academic Clinical Fellowship.

SG, LVL, MDC, MOC CS, MR and JC were supported by the Medical Research Council, the Wellcome Trust and European Union programs (Project GENCODYS no. 241995, Project EUROSPIN no. 242498 and Project SYNSYS no. 242167)

The authors wish to thank Miss Silvia Benito Kwiecinski for disease curation

\section{Author details}

'Molecular Physiology of the Synapse Laboratory, Biomedical Research Institute Sant Pau (IIB Sant Pau), Sant Antoni Ma Claret 167, 08025 Barcelona, Spain. ${ }^{2}$ Universitat Autònoma de Barcelona, 08193 Bellaterra, Cerdanyola del Vallès, Spain. ${ }^{3}$ Department of Biomedical Science, The Centre for Membrane Interactions and Dynamics, University of Sheffield, Western Bank, Sheffield S10 2TN, UK. ${ }^{4}$ Department of Neurology, St George's Hospital, London, UK. ${ }^{5}$ Genes to Cognition Programme, Molecular Neuroscience, Centre for Clinical Brain Science and Centre for Neuroregeneration, University of Edinburgh,
Edinburgh EH16 4SB, UK. 'inguamatics, 324 Cambridge Science Park, Cambridge CB4 OWG, UK. ${ }^{7}$ Academic Department of Neuropathology, Centre for Clinical Brain Sciences, University of Edinburgh, Edinburgh, UK. ${ }^{8}$ Proteomic Mass Spectrometry, The Wellcome Trust Sanger Institute, Hinxton, Cambridgeshire, UK

Received: 31 October 2014 Accepted: 14 November 2014 Published online: 28 November 2014

\section{References}

1. Bayés A, Grant SGN: Neuroproteomics: understanding the molecular organization and complexity of the brain. Nat Rev Neurosci 2009 10:635-646.

2. Bayés A, Van De Lagemaat LN, Collins MO, Croning MDR, Whittle IR, Choudhary JS, Grant SGN: Characterization of the proteome, diseases and evolution of the human postsynaptic density. Nat Neurosci 2011, 14:19-21.

3. Bayés A, Collins MO, Croning MDR, Van De Lagemaat LN, Choudhary JS, Grant SGN: Comparative study of human and mouse postsynaptic proteomes finds high compositional conservation and abundance differences for key synaptic proteins. PLoS One 2012, 7:e46683.

4. Grant SG: Synaptopathies: diseases of the synaptome. Curr Opin Neurobiol 2012, 22:522-529.

5. Hahn C-G, Banerjee A, Macdonald ML, Cho D-S, Kamins J, Nie Z, Borgmann-Winter KE, Grosser T, Pizarro A, Ciccimaro E, Arnold SE, Wang H-Y, Blair IA: The post-synaptic density of human postmortem brain tissues: an experimental study paradigm for neuropsychiatric illnesses. PLoS One 2009, 4:e5251.

6. Macdonald ML, Ciccimaro E, Prakash A, Banerjee A, Seeholzer SH, Blair IA Hahn C-G: Biochemical fractionation and stable isotope dilution liquid chromatography-mass spectrometry for targeted and microdomain-specific protein quantification in human postmortem brain tissue. Mol Cell Proteomics 2012, 11:1670-1681.

7. Chang RYK, Nouwens AS, Dodd PR, Etheridge N: The synaptic proteome in Alzheimer's disease. Alzheimers Dement 2013, 9:499-511.

8. Zhou J, Jones DR, Duong DM, Levey Al, Lah JJ, Peng J: Proteomic analysis of postsynaptic density in Alzheimer's disease. Clin Chim Acta 2013, 420:62-68.

9. Etheridge N, Lewohl JM, Mayfield RD, Harris RA, Dodd PR: Synaptic proteome changes in the superior frontal gyrus and occipital cortex of the alcoholic brain. Proteomics Clin Appl 2009, 3:730-742.

10. Kennedy MB: The postsynaptic density at glutamatergic synapses. Trends Neurosci 1997, 20:264-268.

11. Grant SGN: SnapShot: organizational principles of the postsynaptic proteome. Neuron 2013, 80:534-534.e1.

12. Husi H, Ward MA, Choudhary JS, Blackstock WP, Grant SG: Proteomic analysis of NMDA receptor-adhesion protein signaling complexes. Nat Neurosci 2000, 3:661-669.

13. Fernandez E, Collins MO, Uren RT, Kopanitsa MV, Komiyama NH, Croning MD, Zografos L, Armstrong JD, Choudhary JS, Grant SG: Targeted tandem affinity purification of PSD-95 recovers core postsynaptic complexes and schizophrenia susceptibility proteins. Mol Syst Biol 2009, 5:269.

14. Husi H, Grant SG: Isolation of 2000-kDa complexes of N-methyl-D-aspartate receptor and postsynaptic density 95 from mouse brain. J Neurochem 2001 77:281-291.

15. Kirov G, Pocklington AJ, Holmans P, Ivanov D, Ikeda M, Ruderfer D, Moran J, Chambert K, Toncheva D, Georgieva L, Grozeva D, Fjodorova M, Wollerton R, Rees E, Nikolov I, van de Lagemaat LN, Bayés A, Fernandez E, Olason PI, Böttcher Y, Komiyama NH, Collins MO, Choudhary J, Stefansson K, Stefansson H, Grant SGN, Purcell S, Sklar P, O'Donovan MC, Owen MJ, et al: De novo CNV analysis implicates specific abnormalities of postsynaptic signalling complexes in the pathogenesis of schizophrenia. Mol Psychiatry 2011, 17:142-53.

16. Fromer M, Pocklington AJ, Kavanagh DH, Williams HJ, Dwyer S, Gormley P, Georgieva L, Rees E, Palta P, Ruderfer DM, Carrera N, Humphreys I, Johnson JS, Roussos P, Barker DD, Banks E, Milanova V, Grant SG, Hannon E, Rose SA, Chambert K, Mahajan M, Scolnick EM, Moran JL, Kirov G, Palotie A, McCarroll SA, Holmans P, Sklar P, Owen MJ, et al: De novo mutations in schizophrenia implicate synaptic networks. Nature 2014, 506:179-184.

17. Huguet $\mathrm{G}$, Ey E, Bourgeron $\mathrm{T}$ : The genetic landscapes of autism spectrum disorders. Annu Rev Genomics Hum Genet 2013, 14:191-213. 
18. Pavlowsky A, Chelly J, Billuart P: Emerging major synaptic signaling pathways involved in intellectual disability. Mol Psychiatry 2011, 17:682-693.

19. Migaud M, Charlesworth $P$, Dempster M, Webster LC, Watabe AM, Makhinson M, He Y, Ramsay MF, Morris RG, Morrison JH, O'Dell TJ, Grant SG: Enhanced long-term potentiation and impaired learning in mice with mutant postsynaptic density-95 protein. Nature 1998, 396:433-439.

20. Cuthbert PC, Stanford LE, Coba MP, Ainge JA, Fink AE, Opazo P, Delgado JY, Komiyama NH, O'Dell TJ, Grant SG: Synapse-associated protein 102/dlgh3 couples the NMDA receptor to specific plasticity pathways and learning strategies. J Neurosci 2007, 27:2673-2682.

21. Nithianantharajah J, Komiyama NH, McKechanie A, Johnstone M, Blackwood DH, St Clair D, Emes RD, Van De Lagemaat LN, Saksida LM, Bussey TJ, Grant SGN: Synaptic scaffold evolution generated components of vertebrate cognitive complexity. Nat Publish Group 2013, 16:16-24.

22. Carlin RK, Grab DJ, Cohen RS, Siekevitz P: Isolation and characterization of postsynaptic densities from various brain regions: enrichment of different types of postsynaptic densities. J Cell Biol 1980, 86:831-845

23. Wang Y, TesFaye E, Yasuda RP, Mash DC, Armstrong DM, Wolfe BB: Effects of post-mortem delay on subunits of ionotropic glutamate receptors in human brain. Brain Res Mol Brain Res 2000, 80:123-131.

24. Doyle DA, Lee A, Lewis J, Kim E, Sheng M, MacKinnon R: Crystal structures of a complexed and peptide-free membrane protein-binding domain: molecular basis of peptide recognition by PDZ. Cell 1996, 85:1067-1076.

25. Cohen LD, Zuchman R, Sorokina O, Müller A, Dieterich DC, Armstrong JD, Ziv T, Ziv NE: Metabolic turnover of synaptic proteins: kinetics, interdependencies and implications for synaptic maintenance. PLoS One 2013, 8:e63191.

26. McKusick VA: Mendelian inheritance in man and its online version, OMIM Am J Hum Genet 2007, 80:588-604.

27. Hill WD, Davies G, van de Lagemaat LN, Christoforou A, Marioni RE, Fernandes CPD, Liewald DC, Croning MDR, Payton A, Craig LCA, Whalley $\sqcup$, Horan M, Ollier W, Hansell NK, Wright MJ, Martin NG, Montgomery GW, Steen VM, Le Hellard S, Espeseth T, Lundervold AJ, Reinvang I, Starr JM, Pendleton N, Grant SGN, Bates TC, Deary IJ: Human cognitive ability is influenced by genetic variation in components of postsynaptic signalling complexes assembled by NMDA receptors and MAGUK proteins. Trans/ Psychiatry 2014, 4:e341

28. Coba MP, Pocklington AJ, Collins MO, Kopanitsa MV, Uren RT, Swamy S, Croning MD, Choudhary JS, Grant SG: Neurotransmitters drive combinatorial multistate postsynaptic density networks. Sci Signal 2009, 2:ra19.

29. Villasana LE, Klann E, Tejada-Simon MV: Rapid isolation of synaptoneurosomes and postsynaptic densities from adult mouse hippocampus. J Neurosci Methods 2006, 158:30-36

30. Niethammer $M$, Kim E, Sheng M: Interaction between the $C$ terminus of NMDA receptor subunits and multiple members of the PSD-95 family of membrane-associated guanylate kinases. J Neurosci 1996, 16:2157-2163.

31. Kornau HC, Schenker LT, Kennedy MB, Seeburg PH: Domain interaction between NMDA receptor subunits and the postsynaptic density protein PSD-95. Science 1995, 269:1737-1740.

32. Hsu J-L, Huang S-Y, Chow N-H, Chen S-H: Stable-isotope dimethyl labeling for quantitative proteomics. Anal Chem 2003, 75:6843-6852.

33. Boersema PJ, Aye $T$, van Veen TAB, Heck AJR, Mohammed S: Triplex protein quantification based on stable isotope labeling by peptide dimethylation applied to cell and tissue lysates. Proteomics 2008, 8:4624-4632.

34. Cox J, Mann M: MaxQuant enables high peptide identification rates, individualized p.p.b.-range mass accuracies and proteome-wide protein quantification. Nat Biotechnol 2008, 26:1367-1372.
35. Pagliuca FW, Collins MO, Lichawska A, Zegerman P, Choudhary JS, Pines J: Quantitative proteomics reveals the basis for the biochemical specificity of the cell-cycle machinery. Mol Cell 2011, 43:406-417.

36. Stelzer G, Dalah I, Stein TI, Satanower Y, Rosen N, Nativ N, Oz-Levi D, Olender T, Belinky F, Bahir I, Krug H, Perco P, Mayer B, Kolker E, Safran M, Lancet D: In-silico human genomics with GeneCards. Hum Genomics 2011, 5:709-717.

37. Milward D, Bjäreland M, Hayes W, Maxwell M, Oberg L, Tilford N, Thomas J, Hale R, Knight S, Barnes J: Ontology-based interactive information extraction from scientific abstracts. Comp Funct Genomics 2005, 6:67-71.

doi:10.1186/s13041-014-0088-4

Cite this article as: Bayés et al.: Human post-mortem synapse proteome integrity screening for proteomic studies of postsynaptic complexes. Molecular Brain 2014 7:88.

\section{Submit your next manuscript to BioMed Central and take full advantage of:}

- Convenient online submission

- Thorough peer review

- No space constraints or color figure charges

- Immediate publication on acceptance

- Inclusion in PubMed, CAS, Scopus and Google Scholar

- Research which is freely available for redistribution

Submit your manuscript at www.biomedcentral.com/submit
C Biomed Central 